\title{
Composite slab strength determination approach through reliability analysis
}

\begin{abstract}
The economic use and ease of construction of profiled deck composite slabs faces the challenge of complex and costly strength determination procedures. This is through the longitudinal shear strength determination that shows the level of composite action between the decking sheet and concrete, and a number of methods are available for its determination; the partial shear method is one such method. The Eurocode design provision requires experimental procedures in establishing the shear strength parameter. However, the cost and time constraint associated with the strength verification is a critical issue of major concern that is currently receiving attention. This study proposes to address these challenges by implementing a rational based approach in developing a numerical function for profiled composite slab strength devoid of experimental procedure. The developed methodology is from reliability-based analyses of longitudinal shear load carrying capacity of profiled deck composite slab from partial shear connection method to Eurocode provision. The proposed methodology results indicate good agreement with the performance of full-scale experimental tests.
\end{abstract}

Keyword: Partial shear connection; Reliability; Composite slab; Longitudinal shear; First order reliability method; Strength test 